\title{
Who were the tuberculosis patients who died precociously due to the disease in southern Brazil? A retrospective cohort study.
}

Danielle Talita dos Santos ( $\square$ danielletalita@hotmail.com )

Universidade de Sao Paulo https://orcid.org/0000-0001-9817-7979

\section{Luana Seles Alves}

Universidade de Sao Paulo

Luiz Henrique Arroyo New

Universidade de Sao Paulo

Juliane Almeida Crispim

Universidade de Sao Paulo

Josilene Dália Alves

Universidade de Sao Paulo

Denisse Andrea Cartagena Ramos

Universidade de Sao Paulo

Jonas Bodini Alonso

Universidade de Sao Paulo

Ivaneliza Simionato de Assis

Universidade de Sao Paulo

Antonio Vieira Ramos

Universidade de Sao Paulo

Elma Mathias Dessunti

Universidade Estadual de Londrina Centro de Ciencias da Saude

Ione Carvalho Pinto

Universidade de Sao Paulo

Pedro Fredemir Palha

Universidade de Sao Paulo

Ricardo Alexandre Arcêncio

Universidade de Sao Paulo

Carla Nunes

Universidade Nova de Lisboa

Research article 
Keywords: survival analysis, tuberculosis, HIV, mortality, risk factors

Posted Date: March 26th, 2020

DOI: https://doi.org/10.21203/rs.2.13890/v2

License: (c) (1) This work is licensed under a Creative Commons Attribution 4.0 International License. Read Full License 


\section{Abstract}

BACKGROUND: A diagnosis of tuberculosis (TB) does not necessarily mean that the disease will be treated successfully, as death still occurs among those who are diagnosed by health services. The study aimed to identify the TB patients who died precociously due to the disease and associated factors in southern Brazil.

METHODS: We conducted a retrospective cohort study, where all deaths from TB were gathered, including cases of TB/HIV coinfection (ICD A15.0-A15.9 and ICD B20.0), which occurred between 2008 and 2015 in southern Brazil. After bivariate analysis, techniques for survival analysis were applied, including the Kaplan-Meier test and Cox's regression, from which the mean, median and Cl95\% of survival (in days) were estimated; the hazard ratio (HR) was obtained and the associated causative factors were identified.

RESULTS: A total of 143 patients were analysed: 83 (58\%) of them had a diagnosis of TB (ICD A15.0 to A19) and 60 (42\%) were diagnosed with TB/HIV (ICD B20.0) in basic death cause. The first group (only TB) had a median survival of 21 days, and the second group (TB/HIV) had a median survival of 34 days; however, the difference was not statistically significant. The median survival for the whole sample was 23 days; 82 (57.3\%) of the patients died within 30 days after diagnosis, and 101 (71.3\%) died within 60 days after diagnosis (minimum survival 2 day; maximum 349 days; standard deviation (SD) $=69.5$ and mean $=52.1$ days $)$. Additionally, the alcohol use alcohol use $(\mathrm{HR}=1.65, \mathrm{Cl} 95 \%=1.03-2.68)$ and other comorbidities $(\mathrm{HR}=1.79, \mathrm{Cl} 95 \%=1.13$ - 2.84) were related precocious deaths.

CONCLUSION: Most of the deaths occurred precociously (within two or one months), which indicates that the diagnosis was made too late, when the disease was already at an advanced stage. The use of alcohol and other comorbidities were related with precocious deaths. Although diagnosis and treatment are free in Brazil and the patients had received a diagnosis, they died. Early, sensitive diagnosis, with social support and comprehensive care might reduce early mortality among patients with addiction problems.

\section{Background}

Even though the treatment of tuberculosis (TB) has been established since the late 1940s, the illness is still one of the top 10 causes of death by disease globally [1]. In 2017, a total of 1.3 million HIV-negative people, in addition to some 300000 people living with HIV/AIDS (PLWHA), died as a result of TB [1]. At present, a group of 30 countries accounts for $84 \%$ of TB cases worldwide, and Brazil is currently in $19^{\text {th }}$ place in this world ranking [1]. In Brazil, the mortality rate as a result of TB was 2.2 deaths for every 100,000 people in 2017 , and the prevalence of the disease was $32.4 / 100,000$ inhabitants [2].

TB is the main cause of death among PLWHA [1,3], and the risk of dying from TB is up to 10.6-fold higher in this group, when compared with the general population under study [3]. Mortality from TB is also higher among people with comorbidities such as diabetes mellitus and risk factors such as alcohol consumption and tobacco smoking $[4,5,6]$. Other factors have also been identified as possible causes, 
such as age, being male, having a lower educational level, as well as socio-economic factors such as the location of one's abode and social conditions [4,7].

Studies using the technique of survival analysis have found that death from TB is most common in the first three months after diagnosis among patients with coinfection with human immunodeficiency virus and TB (TB/HIV) [8], while another study observed that the majority of deaths took place within two months after the start of treatment for TB [3]. A study investigating an HIV-negative population found that the median survival was 12 days, considering those who died of TB [9].

Some studies that evaluated survival in relation to TB focused mainly on people with TB/HIV coinfection $[3,8,10,11]$ and on the delay in the commencement of treatment for TB, considering the period from diagnosis to the start of antituberculosis activities $[8,12]$. Some studies have addressed the issue of premature deaths from TB $[9,11,13]$, considering those deaths which occurred in the intensive stage of treatment, which comprises the first two months of treatment $[9,14]$. Some researchers have analysed premature death and found low BMI and elevated respiratory rate [9]; moreover, subjects with an undetectable baseline $\mathrm{CD} 4$ lymphocyte count $(\mathrm{HR}=9.39,95 \% \mathrm{Cl}=2.56-34.5)$ had higher mortality [10], and TB deaths occurred in patients with advanced age and comorbid illnesses [13].

Thus, there is a knowledge gap in the analysis of premature death from the moment of diagnosis up to the moment of death from TB, as well as the associated factors. This would serve to advance existing knowledge on the topic and improve the control of this disease in Brazil [15,16]. It is also relevant to establish the survival time and the factors related to premature mortality among TB patients. In the light of the points raised here, this study aimed to identify the TB patients who died precociously due to the disease, the time survived and associated factors in southern Brazil.

\section{Methods}

\section{Study design and population}

This was a retrospective cohort study, consisting of survival analysis. The population was made up of cases of death from tuberculosis and TB associated with HIV (TB/HIV) which occurred between 2008 and 2015 in a municipality in the south of Brazil.

\section{Inclusion and exclusion criteria}

Were included in the survival analysis cases registered with a certificate of death from the Mortality Information System (MIS), with the basic cause of death registered under CID 10 codes A 15.0 to 19.0 (tuberculosis) and B 20.0: HIV disease resulting in tuberculosis (TB/HIV). To analysis the survival, patients under 18 years of age, and in which death occurred equal or less 1 day after diagnoses were excluded in the study. For reasons the State Death Commission analysed the death cases and defined the diagnosis based on the registered disease and clinical history after death. More than one criterion was 
adopted to exclude the analysed cases: one year after treatment death occurred. The national TB control programme in Brazil recommends the maximum 9 months period of treatment, for this reason we understood that over twelve months to finalise treatment in System, can be inconsistent data, being excluded in the study.

\section{Place of study}

The region of the study was the south of Brazil, and the cohort studied corresponded to the municipality of Curitiba, the capital of the State of Paraná, with an estimated population of 1,971,185 people and a demographic density of 4,027.04 people per square kilometre [17]. This is a Brazilian state capital with a Human Development Index ( $\mathrm{HDI}$ ) of 0.823 , placing Curitiba in tenth place on the national ranking. The percentage of people considered poor stood at $1.73 \%$, while $7.93 \%$ of the population was vulnerable to poverty, and the GINI Index stood at 0.55 [18]. Within the municipality of Curitiba, the municipality had the following coefficients: prevalence of 14 cases per 100,000 people, and mortality of 1.2 per 100,000 people [19]. The deaths were clustered in the southern region of the municipality and were associated with low HDIs in the respective regions [20].

\section{Data source and procedures}

The data were obtained from the Mortality Information System (MIS) and from the Disease Notification Information System (DNIS). All analysed variables were obtained from this site and were controlled by the Secretariat of Health of the State of Paraná (SESA). Information from the latter source completed the clinical and operational picture regarding TB.

\section{Variables under study}

The main variable under analysis was the total time (in days) that elapsed between the date on which the diagnosis of TB was confirmed and the date of death as a result of TB. Deaths that occurred within the first 60 days after diagnosis were considered as premature or precocious, in agreement with the authors $[9,14]$. Additionally, a comparison was made between the cut-off time points of 30 days and 60 days to death. The independent variables included social and demographic dimensions, as well as clinical and operational variables.

Table 1 Source of data and independent variables under study

*Source: Mortality Information System -MIS 
**Source: Disease Notification Information System - DNIS

\section{Linkage of databases}

We established linkage between the MIS and DNIS databases, so as to obtain the clinical and operational variables in addition to the date of diagnosis of TB as obtained from SINAN. In this procedure, we considered the keys, which are the elements of information that identify the registration number, date of birth and identification of the mother, in a unique manner. For the application of this technique, we used SPSS software, version 24.0 (IBM Corp. Released 2016. IBM SPSS Statistics for Windows, Version 24.0. Armonk, NY: IBM Corp.).

\section{Data analysis}

We applied descriptive statistics in order to obtain the absolute values and percentage frequencies of the categorical variables. In the case of continuous variables (time in days and age) we obtained the minimum and maximum values, arithmetic mean, median and standard deviation (SD). Firstly, two cutoffs ( 30 days and 60 days between diagnosis and TB death) were adopted assess the behaviour of the variables.

To analyse the relationship between time death and variables, we carried out a Cox proportional hazards regression model $[21,22,23]$. First, we performed a bivariate analysis, by which we identified the variables of interest for inclusion in the multivariate model. The criteria we used for this selection were variables with $p<0.25$. Then, we selected the best multivariate model considering the lowest Akaike information criterion (AIC) value, using the backward elimination method. At the end of the analysis, we carried out the test of proportional hazards assumption for the Cox regression model fit for each covariate.

The results are shown as hazard ratios (HR) with right censored data, with confidence intervals of $95 \%$ (Cl95\%). A type I error rate of $5 \%$ was also established, considering results with $p<0.05$ as statistically significant. The analysis was carried out using the SPSS and R software, versions 24.0 (IBM) and 3.6.1, respectively.

The study was approved by the Research Ethics Committee of São Paulo University (USP), under number CAAE No. 64515717.9.0000.5393.

\section{Results}

Were included in the analysis, 143 cases; Firstly, we compiled total of 205 cases, of which 131 (63.9\%) had a diagnosis of TB (ICD A15-A19) and 74 (36.1\%) were diagnosed 
with TB/HIV (ICD B20.0) as the main cause of death in the files. Linkage was also established between MIS and DNIS for 179 (87.3\%) of the cases. After criterion exclusion was adopted, 143 cases were included in the analysis; thus, we considered the these cases of death (Table 1). Figure 1 provides a flow chart presenting the cases of death analysed in this study.

Figure 1- Flow chart of deaths analysed in this study

Out of the 143 deaths that occurred and were analysed in the studied period, 83 (58\%) of them had a diagnosis of TB (ICD A15.0 to A19) and 60 (42\%) were diagnosed with TB/HIV (ICD B20.0). The descriptive results are shown in Table 2, where one can see that most cases, i.e. 112 (78.3\%), occurred in males. The white race prevailed among the deaths, with 93(69.9\%) cases, while the mean age was 47 (minimum 20, maximum 83, median $=46$ and SD $=14$ )

Table 2- Distribution of social, clinical and operational characteristics of the patients who died as a result of TB and TB/HIV in Curitiba, shown in groups according to number of days to TB death (2008-2015). 


\begin{tabular}{|c|c|c|c|c|c|c|c|}
\hline \multirow[b]{2}{*}{ Variables } & \multirow[b]{2}{*}{ Categories } & \multicolumn{2}{|c|}{$\begin{array}{c}\text { Death }<30 \text { days } \\
\text { (cut-off })\end{array}$} & \multicolumn{2}{|c|}{$\begin{array}{c}\text { Death }<60 \text { days } \\
\text { (cut-off) }\end{array}$} & \multicolumn{2}{|c|}{ All deaths } \\
\hline & & $\mathrm{n}(82)$ & (\%) & $\mathrm{n}(101)$ & $\%$ & $N(143)$ & (\%) \\
\hline \multirow{2}{*}{$\begin{array}{l}\text { Coinfection (basic } \\
\text { cause) }\end{array}$} & Yes TB/HIV & 29 & 35.4 & 38 & 37.6 & 60 & 42.0 \\
\hline & No (only TB) & 53 & 64.6 & 63 & 62.4 & 83 & 58.0 \\
\hline \multirow[t]{2}{*}{ Sex $(143)$} & Female & 19 & 23.2 & 24 & 23.8 & 31 & 21.7 \\
\hline & Male & 63 & 76.8 & 77 & 76.2 & 112 & 78.3 \\
\hline \multirow[t]{3}{*}{ Ethnicity (133) } & White or Oriental & 57 & 69.5 & 66 & 65.3 & 93 & 65,0 \\
\hline & Afro descendant & 19 & 23.2 & 27 & 26.7 & 40 & 28,0 \\
\hline & Not informed & 06 & 7.3 & 08 & 7.9 & 10 & 7.0 \\
\hline \multirow[t]{3}{*}{ Educational level } & 0-7 years of schooling & 47 & 57.3 & 57 & 56.4 & 82 & 57,3 \\
\hline & 8 or more years of schooling & 22 & 26.8 & 28 & 27.7 & 41 & 28,7 \\
\hline & Not informed & 13 & 15.9 & 16 & 15.8 & 20 & 14.0 \\
\hline \multirow[t]{3}{*}{ Marital status } & Married/common law marriage & 24 & 29.3 & 31 & 30.7 & 45 & 31,5 \\
\hline & $\begin{array}{l}\text { Single/widowed/separated or } \\
\text { divorced }\end{array}$ & 48 & 58.5 & 56 & 55.4 & 82 & 57,3 \\
\hline & Not informed & 10 & 12.2 & 14 & 13.9 & 16 & 11,2 \\
\hline \multirow[t]{3}{*}{ Type of entry } & New case & 69 & 84.1 & 82 & 81.2 & 112 & 78,3 \\
\hline & Re-entry or retreatment & 10 & 12.2 & 14 & 13.9 & 25 & 17,5 \\
\hline & Not informed & 03 & 3.7 & 05 & 5.0 & 06 & 4.2 \\
\hline \multirow[t]{3}{*}{ Institutionalised } & No & 61 & 74.4 & 76 & 75.2 & 113 & 79,0 \\
\hline & Yes & 11 & 13.4 & 14 & 13.9 & 16 & 11,2 \\
\hline & Not informed & 10 & 12.2 & 11 & 10.9 & 14 & 9.8 \\
\hline \multirow{4}{*}{$\begin{array}{l}\text { X-ray confirmation of } \\
\text { diagnosis } \\
\text { Clinical form }\end{array}$} & No & 12 & 14.6 & 13 & 12.9 & 22 & 15,4 \\
\hline & Yes/suspicious & 70 & 85.4 & 88 & 87.1 & 121 & 84.6 \\
\hline & Pulmonary & 61 & 74.4 & 75 & 74.3 & 103 & 72.0 \\
\hline & Extrapulmonary & 21 & 25.6 & 26 & 25.7 & 40 & 28.0 \\
\hline \multirow[t]{3}{*}{ Use of alcohol } & No & 47 & 57.7 & 56 & 55.4 & 89 & 62,2 \\
\hline & Yes & 30 & 36.6 & 40 & 39.6 & 48 & 33,6 \\
\hline & Not informed & 05 & 6.1 & 05 & 5.0 & 06 & 4.2 \\
\hline \multirow[t]{3}{*}{ Diabetes mellitus (DM) } & No & 75 & 91.5 & 93 & 92.1 & 133 & 93,0 \\
\hline & Yes & 02 & 2.4 & 02 & 2.0 & 03 & 2.1 \\
\hline & Not informed & 05 & 6.1 & 06 & 5.9 & 07 & 4.9 \\
\hline \multirow[t]{3}{*}{ Bacilloscopy } & Negative & 23 & 28.0 & 28 & 27.7 & 40 & 28,0 \\
\hline & Positive & 45 & 54.9 & 58 & 57.4 & 78 & 54,5 \\
\hline & Not informed & 14 & 17.1 & 15 & 14.9 & 25 & 17.5 \\
\hline \multirow{3}{*}{$\begin{array}{l}\text { Sputum culture } \\
(40)\end{array}$} & Negative & 07 & 8.5 & 10 & 9.9 & 20 & 14,0 \\
\hline & Positive & 08 & 9.8 & 11 & 10.9 & 20 & 14.0 \\
\hline & Not informed & 67 & 81.7 & 80 & 79.2 & 103 & 72,0 \\
\hline \multirow[t]{3}{*}{ Rifampicin } & No & 03 & 3.7 & 03 & 3.3 & 05 & 3.5 \\
\hline & Yes & 70 & 85.4 & 88 & 87.1 & 126 & 88,1 \\
\hline & Not informed & 09 & 11.0 & 10 & 9.9 & 12 & 8.4 \\
\hline \multirow[t]{3}{*}{ Isoniazid } & No & 03 & 3.7 & 03 & 3.3 & 05 & 3.5 \\
\hline & Yes & 70 & 85.4 & 88 & 87.1 & 126 & 88,1 \\
\hline & Not informed & 09 & 11.0 & 10 & 9.9 & 12 & 8.4 \\
\hline \multirow[t]{3}{*}{ Pyrazinamide } & No & 05 & 6.1 & 05 & 5.0 & 06 & 4,2 \\
\hline & Yes & 68 & 82.9 & 86 & 85.1 & 125 & 87,4 \\
\hline & Not informed & 09 & 11.0 & 10 & 9.9 & 12 & 8.4 \\
\hline
\end{tabular}




\begin{tabular}{|c|c|c|c|c|c|c|c|}
\hline \multirow[t]{3}{*}{ Ethambutol } & No & 21 & 25.6 & 25 & 24.8 & 36 & 25,2 \\
\hline & Yes & 52 & 63.4 & 66 & 65.3 & 95 & 66,4 \\
\hline & Not informed & 09 & 11.0 & 10 & 9.9 & 12 & 8.4 \\
\hline \multirow[t]{3}{*}{ Streptomycin } & No & 72 & 87.8 & 90 & 89.1 & 128 & 89,5 \\
\hline & Yes & 01 & 1.2 & 01 & 1.0 & 03 & 2.1 \\
\hline & Not informed & 09 & 11.0 & 10 & 9.9 & 12 & 8.4 \\
\hline \multirow[t]{3}{*}{ Ethionamide } & No & 72 & 87.8 & 90 & 89.1 & 130 & 90,9 \\
\hline & Yes & - & & - & - & & \\
\hline & Not informed & 10 & 12.2 & 11 & 10.9 & 13 & 9.1 \\
\hline \multirow{3}{*}{$\begin{array}{l}\text { Medication used: other } \\
\text { drugs }\end{array}$} & No & 68 & 82.9 & 84 & 93.2 & 119 & 83,2 \\
\hline & Yes & 01 & 1.2 & 02 & 2.0 & 07 & 4,9 \\
\hline & Not informed & 13 & 15.9 & 15 & 14.9 & 17 & 11.9 \\
\hline \multirow[t]{3}{*}{ Supervised treatment } & No & 10 & 12.2 & 11 & 10.9 & 18 & 12,6 \\
\hline & Yes & 63 & 76.8 & 78 & 77.2 & 111 & 77,6 \\
\hline & Not informed & 09 & 11.0 & 12 & 11.9 & 14 & 9.8 \\
\hline
\end{tabular}

The most common clinical presentation was pulmonary TB, with 103 cases (72\%). There were a total of 112 new cases (81.8\%), and in 121 of the cases (84.6\%) the diagnosis was confirmed by radiographic examination.

When we compared the different groups according delay between diagnoses and death (cut-off 30 days, and 60 days) we can observe similarities. Thus, was chosen the cutoff group most relevant to the next analyse based on the best result.

The overall medial survival, was 23 days; it was also observed that 82 (57.3\%) of the patients died within 30 days after diagnosis, and 101 (71.3\%) died within 60 days after diagnosis (minimum survival 2 day; maximum 349 days; standard deviation (SD) $=69.5$ and mean $=52.1$ days .

After the initial selection of variables from the bivariate analysis (Table 2), these were inserted in the multivariate model for the survival analysis.

Table 3- Bivariate analysis between social, clinical and operational characteristics of the patients who died as a result of TB and TB/HIV in Curitiba, shown in groups (cut-off) 
according to number of days to TB death (2008-2015).

\begin{tabular}{|c|c|c|c|c|}
\hline & \multicolumn{2}{|c|}{ Death $<30$ days (cut-off) } & \multicolumn{2}{|c|}{ Death $<60$ days (cut-off) } \\
\hline Variables & chi-squared & p-value & chi-squared & p-value \\
\hline Basic cause (TB/HIV) & 3.43 & 0.046 & 2.65 & 0.07 \\
\hline Sex & 0.25 & 0.38 & 0.88 & 0.24 \\
\hline Ethnicity & 2.17 & 0.10 & 0.16 & 0.41 \\
\hline Educational level & 0.15 & 0.42 & 0.02 & 0.52 \\
\hline Marital status & 0.32 & 0.35 & 2.88 & 0.55 \\
\hline Type of entry & 3.90 & 0.040 & 0.09 & 0.07 \\
\hline Institutionalised & 1.23 & 0.20 & 2.72 & 0.08 \\
\hline X-Ray confirmation of diagnosis & 1.09 & 0.236 & - & - \\
\hline Clinical form & 0.53 & 0.29 & 0.84 & 0.23 \\
\hline Alcohol use & 1.19 & 0.181 & 6.19 & 0.01 \\
\hline $\mathrm{DM}$ & 0.12 & 0.599 & 0.01 & 0.66 \\
\hline Other comorbidities & 7.85 & 0.004 & 3.26 & 0.05 \\
\hline Bacilloscopy & 0.0 & 0.56 & 0.25 & 0.38 \\
\hline Sputum culture & 0.17 & 0.50 & 0.10 & 0.50 \\
\hline Rifampicin & 0.04 & 0.60 & 0.22 & 0.48 \\
\hline Isoniazid & 0.04 & 0.60 & 0.22 & 0.48 \\
\hline Pyrazinamide & 1.94 & 0.17 & 0.57 & 0.40 \\
\hline Ethambutol & 0.14 & 0.43 & 0.0 & 0.57 \\
\hline Streptomycin & 0.62 & 0.41 & 1.89 & 0.22 \\
\hline Medication used: Other drugs & 4.90 & 0.033 & 5.38 & 0.03 \\
\hline Supervised treatment (DOTS) & 0.01 & 0.56 & 0.61 & 0.30 \\
\hline
\end{tabular}

Table 4 - Results of the Cox proportional hazards regression model of patients who died of TB and TB/HIV and social, clinical and operational variables, Curitiba (2008-2016). 


\begin{tabular}{lcccc} 
Variables & coefficient & HR & CI95\% & p value \\
\hline TB/HIV coinfection & & & & \\
No & 1 & 1 & & \\
Yes & -0.40 & 0.06 & $0.41-1.07$ & 0.09 \\
Type of entry & & & & \\
new case & 1 & 1 & - & - \\
relapse & -0.59 & 0.55 & $0.30-1.01$ & 0.06 \\
Alcohol use & & & & \\
No & 1 & 1 & - & - \\
Yes & 0.50 & 1.65 & $1.03-2.68$ & $\mathbf{0 . 0 4}$ \\
Other diseases & & & & \\
No & 1 & 1 & - & - \\
Yes & 0.58 & 1.79 & $1.13-2.84$ & $\mathbf{0 . 0 1}$ \\
\hline
\end{tabular}

We carried out a multivariate model by inserting the selected variables. The results of the survival analysis are shown in Table 3. The model presented as variables associated with early mortality the alcohol use $(H R=1.65, C I 95 \%=1.03-2.68)$ and other associated comorbidities $(\mathrm{HR}=1.79$, CI95\%=1.13 - 2.84).

To evaluate the validity of the Cox model assumptions, we performed the respective test, which is shown in Table 4 . The test of proportional hazards assumption showed no violation of the Cox model assumptions, indicating the suitability of the final model.

Table 5 - Results of the test of proportional hazards assumption of the Cox regression model fit, Curitiba (2008-2016).

\begin{tabular}{lccc}
\hline Variables & chisq & df & p value \\
\hline Type of entry & 8.29 & 1 & 0.58 \\
Use alcohol & 1.68 & 1 & 0.19 \\
Other diseases & 3.52 & 1 & 0.06 \\
Global & 6.53 & 3 & $\mathbf{0 . 0 8}$ \\
\hline
\end{tabular}

Figure 2 Curves obtained in the Kaplan-Meier survival analysis, with regard to disease aggravation by alcohol consumption in patients who died of TB and TB-HIV. Curitiba 
Figure 3 Curves obtained in the Kaplan-Meier survival analysis, with regard to disease aggravation by others comorbidities in patients who died of TB and TB-HIV. Curitiba (20082016).

\section{Discussion}

The study identified that precocious deaths due to tuberculosis were associated with alcohol consumption and other comorbidities. The associated variables in the bivariate analysis were basic cause (TB/HIV), type of entry, whether the patient was institutionalised, clinical form and medication used (other drugs).

Alcohol use has a known association with tuberculosis [31]. One study performed in the same Brazilian state showed an association between outcomes, i.e. not cured with alcoholism, confirming the importance this characteristic in patients with TB in this region [32]. One metanalysis [33] found that the use of alcohol was linked to a greater risk (RR 1.35, Cl95\% 1,09-1,68) of progression from TB infection to TB disease when compared with those who not use substance. In addition, the risk of the disease developing increased together with an increase in the consumption of ethanol (in grams per day).

There are also other factors that could be linked to the use of alcohol, such as malnutrition, overcrowded housing and use of other substances [33,34]. Additionally, alcohol use disrupts the immune response, increasing susceptibility to respiratory diseases such as tuberculosis $[9,35]$.

The variable on other comorbidities included several chronic diseases that were not specifically mentioned in the Information System questionnaire, but could include arterial hypertension, metabolic diseases, psychiatric disorders and others. There is a need recognise the complexity of individual and social conditions that can influence TB transmission, development and mortality [32-34]. Mortality due to TB often is associated with several medical conditions, in this study, this variable expresses multifactorial process $[33,34]$.

One of the objectives of this study was to assess patient survival time. It was found that most of the deaths occurred within two months, and comparing the two cut-offs provided similar results. Late TB diagnosis may explain the premature deaths we found in our study. Some studies $[9,13,14]$ have investigated the phenomenon of premature death among patients with TB. One such study in Korea observed similar results with a median survival time of 21 days [13]; another study found that $19 \%$ of the patients died within 7 days and $41 \%$ died within the first month after the start of treatment for TB [14]. Another study, performed in Africa, found a mean survival span of two months in $53.3 \%$ of the people who started their TB treatment; in this case, mortality among HIV-positive people was higher than for those who were HIV-negative or whose HIV status was unknown [3]. 
The short survival period found (less than a month) points to the severity of the disease at the moment of diagnosis $[9,10]$. Another study found a higher percentage of treatment abandonment and a lower rate of cure in those Brazilian municipalities where the DOTS strategy was more widely applied; in contrast, those municipalities that made less use of the strategy obtained poorer results [24].

The difficulty in accessing services at the moment of symptom onset [13], especially in vulnerable groups or when health service providers are not qualified to recognise a cough as being a clinical sign of TB, should be borne in mind [25]. This result suggests the need for an attention model that gives higher value to the active search for patients within the territories, and the tracking of TB among the population at large, and through regular appointments for patients living with HIV [15,16,24].

Brazil has a special protocol in place for monitoring the deaths that occur with some mention of TB as one of the causes, a protocol which, among other aims, seeks to investigate the individual health conditions in these patients and their access to health services, as well as to analyse and correct the information that appears in the different information systems used, namely DNIS, MIS and the TB site [16]. This is a strategic initiative to improve the qualification of the data; however, according to evidence from the present study, it is important to verify the phase at which the patient passed away, in a stratified fashion, whether the case was being monitored by the service and if this happened in the early or the later phase of treatment. This is important because, depending on the phase at which the patient met his or her demise, actions also need to be modulated, as premature death makes us think about whether measures and protocols have been effectively implemented so as to impact on mortality from TB [28].

The difference in survival between people with TB and those with TB/HIV did not show any statistical significance, even though the median of the group with coinfection was higher, meaning that they survived longer than the group that only had TB. One point that could justify this result is the fact that people living with HIV/AIDS often receive ongoing medical monitoring from a multiprofessional team, including medical appointments, examinations and regular administration of medication, which leads to intermittent contact with health professionals and also increases opportunities for recognition of signs and symptoms of TB. This, in fact, is recommended as part of the protocol of caring for these patients, i.e. the investigation of TB at every medical appointment [15].

Due to monitoring in health services and antiretroviral therapy, PLWHA could be afforded some protection when compared with groups that did not receive any monitoring, which would justify the longer survival within this group in the present report [15].

One of the limitations of this study is the small sample size; therefore, the generalisability might be limited. Other limitations are related to the use of secondary data that were entered into the form in advance, as there were gaps in form-filling or missing information. Only recently $(2017)[2,16]$ was the protocol launched for monitoring deaths with a mention of TB. One of the purposes of this was to correct, both quantitatively and qualitatively, the information that appeared in the different information systems, DNIS and MIS. 


\section{Conclusion}

The study found deaths from TB occurring prematurely, which points to the possibility of a tardy diagnosis of the disease, at a more advanced phase. The consumption of alcohol and other comorbidities also increased the risk of premature death from TB. These deaths should be avoided through the adoption of the actions mentioned in the programmes for the control of TB, such as the application of DOTS supervised treatment, the intensification of active screening and the tracking of possible cases that could lead to worse disease outcomes and premature death. The physicians, nurses and other professional can look more closely these patients for improving this outcome. TB is an old disease, yet one that is still present; at one time it was a synonym for death, and it is not acceptable that this disease should continue to end lives in this day and age, especially considering patients who have already been diagnosed and who could have received the necessary intervention, so that the outcome of death could have been avoided.

\section{Declarations}

\section{Ethics approval and consent to participate:}

The study was approved by the Institutional Review Board at the University of Sao Paulo (USP) under CAAE No. 64515717.9.0000.5393. Informed consent was not required, as data were based on official data sets and were previously anonymised.

Consent for publication: Not Applicable

\section{Availability of data and material:}

The database is carried out by the Epidemiological Surveillance Division and Secretary of Health of the State of Parana, Brazil and restrictions apply to the availability of these data, which were used under license for the current study, so are not publicly available. The first author had registered with details as well as contact data in case of interest in collaborative work or further information.

\section{Competing interests:}

The authors declare that they have no competing interests.

\section{Funding:}

Coordenação de Aperfeiçoamento de Pessoal de Nível Superior (CAPES) (Processo: Programa de Doutorado Sanduíche no Exterior -88881.132524/2016-01) and CNPQ (Bolsa produtividade em pesquisa - Grant 305236/2015-6); Fundação de Amparo a Pesquisa do Estado de São Paulo -FAPESP (process 2015/17586-3) support for collection data.

\section{Author contributions:}


Nunes $C$ and Santos DT conceived the study. Santos DT, Alves LS, collected and initially computed the data. Santos, DT, Nunes C, Alonso JB, Arroyo Luiz H, and Arcencio RA analysed and constructed the results from the data. Santos DT, Nunes $C$, Arcencio RA and Cartagena D writing the manuscript. Crispim, J, Alves JD, Ramos AV, Dessunti EM, Pinto IC and Palha PF reviewed and edited the manuscript. All authors read and approved the final manuscript.

\section{Acknowledgements}

The authors would like to thank the Epidemiological Surveillance Division and Secretary of Health of the State of Parana for making the data available.

\section{References}

1 Global tuberculosis report 2018. Geneva: World Health Organization; 2018. Licence: CC BY-NC-SA 3.0 IGO. WHO/CDS/TB/2018.20.

2 Brasil, Ministério da Saúde. Boletim Epidemiológico 2017. Secretaria de Vigilância em Saúde Departamento de Vigilância, Prevenção e Controle das Infecções Sexualmente Transmissíveis, do HIV/Aids e das Hepatites Virais. Brasil, 2017.

3 Onyango DO, Yuen CM, Cain KP, Ngari F, Masini EO, Borgdorff MW. Reduction of HIV-associated excess mortality by antiretroviral treatment among tuberculosis patients in Kenya. PLoS One. 2017;12 (11):e0188235.

4 Silva DR, Muñoz-Torrico M, Duarte R, Galvão T, Bonini EH, Ferlin F, et al. Fatores de risco para tuberculose: diabetes, tabagismo, álcool e uso de outras drogas. J Bras Pneumol 2018; 44(2):145-152.

5 Parry C, Ferreira-Borges C, Poznyak V, Lönnroth K, Rehm J. The international study on alcohol and infectious diseases: three priorities for research. Addiction 2013; 108:1-2.

6 Marais BJ, Lönnroth K, Lawn SD, Migliori GB, Mwaba P, Glaziou P, et al. Tuberculosis comorbidity with communicable and non-communicable diseases: integrating health services and control efforts. Lancet Infect Dis 2013;13:436-48. 
7 Berra TZ, Queiroz AAR, Yamamura M, Arroyo LH, Garcia MCC, Popolin MP et al. Spatial risk of tuberculosis mortality and social vulnerability in Northeast Brazil. Rev Soc Bras Med Trop 2017; 50(5):693-697.

8 Nogueira BMF, Rolla VC, Akrami KM, Kiene SM. Factors associated with tuberculosis treatment delay in patients co-infected with HIV in a high prevalence area in Brazil. PLoS ONE 2018; 13(8): e0202292.

9 Waitt CJ, Banda NPK, White SA, Kampmann B, Kumwenda J, Heyderman RS, et al. Early deaths during tuberculosis treatment are associated with depressed innate responses, bacterial infection, and tuberculosis progression. J Infect Dis 2001; 204(3):358-362.

10 Schmaltz CA, Santoro-Lopes G, Lourenço MC, Morgado MG, Velasque LS, Rolla VC. Factors impacting early mortality in tuberculosis/HIV patients: differences between subjects naïve to and previously started on HAART. PLoS One 2012;7(9):e45704.

11 Escada ROS, Velasque L, Ribeiro SR, Cardoso SW, Marins LMS, Ginsztejn E, et al. Mortality in patients with HIV-1 and tuberculosis co-infection in Rio de Janeiro, Brazil - associated factors and causes of death. BMC Infect Dis 2017; 17: 373.

12 Seid A, Metaferia Y. Factors associated with treatment delay among newly diagnosed tuberculosis patients in Dessie city and surroundings, Northern Central Ethiopia: a cross-sectional study. BMC Public Health 2018;18(1):931-9.

13 Lee J, Nam HW, Choi SH, Yoo SS, Lee SY, Cha SI, et al. Comparison of early and late tuberculosis deaths in Korea. J Korean Med Sci 2017;32:700-703.

14 Harries AD, N J Hargreaves, F Gausi, JH Kwanjana, FM Salaniponi. High early death rate in tuberculosis patients in Malawi. Int J Tuberc Lung Dis 2011; 5(11):1000-1005. 
15 Ministério da Saúde. Recomendações para o manejo da coinfecção TB-HIV em serviços de atenção especializada a pessoas vivendo com HIV/AIDS/Ministério da Saúde. Secretaria-Executiva. Brasília: Ministério da Saúde, 2013.

16 Ministério da Saúde. Secretaria de Vigilância em Saúde. Departamento de Vigilância das Doenças Transmissíveis. Plano nacional pelo fim da tuberculose. Brasília: Ministério da Saúde; 2017.

17 Instituto Brasileiro de Geografia e Estatística. Panorama cidades. https://cidades.ibge.gov.br/brasil/pr/curitiba/panorama (acessado em 08/Nov/2018).

18 Programa das Nações Unidas para o Desenvolvimento PNUD. Instituto de pesquisa Economica Aplicada IPEA. Atlas do Desenvolvimento Humano no Brasil. http://www.atlasbrasil.org.br/2013/pt/perfil_m/curitiba_pr (acessado em 10/Nov/2018).

19 Ministério da Saúde. Secretaria de Vigilância em Saúde. Boletim Epidemiológico nº 11. mar 2018, v 44.

20 Santos DT, Nunes C, Alves LS, Queiroz AAR, Miranda M J, Arroyo LH, et al. Is there association between human development index and tuberculosis mortality risk? Evidence from a spatial analysis study in the south of Brazil. Epidemiol. and Infection 2018;1-8.

21 Guo S, Zeng D. An overview of semiparametric models in survival analysis. Journal of Stat. Plan. and Inference 2014; 151-152.

22 Ferreira JC, P CM. O que é análise de sobrevida e quando devo utilizá-la? J Bras Pneumol. 2016;42(1):77-77.

23 Glantz SA. How to analyse survival data. In: Glantz SA. Primer in Biostatistics. 7th ed. New York: McGraw-Hill Medical; 2011. p 229-44. 
24 Arakawa T, Magnabosco GT, Andrade RLP, Brunello MEF, Monroe AA, Ruffino-Netto A, et al . Programa de controle da tuberculose no contexto municipal: avaliação de desempenho. Rev. Saúde Pública 2017; 51(23):1-9.

25 Loureiro RB, Villa TCS, Ruffino-Netto A, Peres RL, Braga JU, Zandonade E, et al. Acesso ao diagnóstico da tuberculose em serviços de saúde do município de Vitória, ES, Brasil. Ciênc. saúde coletiva 2014;19 (04)1233-1244.

26 Mulenga C, Mwakazanga D, Vereecken K, Khondowe S, Kapata N, Chola I, et al. Management of pulmonary tuberculosis patients in an urban setting in Zambia: a patient's perspective. BMC Public Health 2010;10(756):1-8.

27 Bisallah Cl, Rampal L, Lye MS, Mohd SS, Ibrahim N, lliyasu Z, et al. Effectiveness of health education intervention in improving knowledge, attitude, and practices regarding Tuberculosis among HIV patients in General Hospital Minna, Nigeria - A randomized control trial. PLoS One 2018;13(2):e0192276.

28 Getahun B, Ameni G, Biadgilign S, Medhin G. Mortality and associated risk factors in a cohort of tuberculosis patients treated under DOTS programme in Addis Ababa, Ethiopia. BMC Infect Dis 2011;11(127):1-8.

29 Dizaji MK, Kazemnejad A, Tabarsi P, Zayeri F. Risk factors associated with survival of pulmonary tuberculosis. Iran J Public Health. 2018;47(7):980-987.

30 Miller TL, Wilson FA, Pang JW, Beavers S, Hoger S, Sharnprapai S, et al. Mortality hazard and survival after tuberculosis treatment. Am. Journal of Public Health 2015; 105(5): 930-7.

31 Word Health Organization. Definitions and reporting framework for tuberculosis 2013 Revision. World Health Organization; 2013. 
32 Souza DCS, Oliveira KS, Andrade RLP, Scatena RM, Silva-Sobrinho RA. Aspects related to the outcomes of the treatment, in international borders, of cases of tuberculosis as associated to comorbidities. Rev. Gaúcha Enferm. 2019; 4:e20190050.

33 Imtiaz S, Shield KD, Roerecke M, Samokhvalov AV, Lönnroth K, Rehm J. Alcohol consumption as a risk factor for tuberculosis: meta-analyses and burden of disease. Eur Respir J. 2017;50(1):1700216.

34 Lönnroth K, Williams B, Stadlin S, Jaramillo E, Dye C. Alcohol use as a risk factor for tuberculosis - a systematic review. BMC Public Health 2008;8:289.

35 Rehm J, Samokhvalov AV, Neuman MG, Room R, Parry C, Lönnroth K, et al. The association between alcohol use, alcohol use disorders and tuberculosis (TB). A systematic review. BMC Public Health 2009;9:450.

36 Molina PE, Happel KI, Zhang P, Kolls JK, Nelson S. Focus on: Alcohol and the immune system. Alcohol Res Health. 2010;33(1-2):97-108

37 Rabahi MF, Silva Júnior JLR, Ferreira ACG, Tannus-Silva DGS, Conde MB. Tratamento da tuberculose. J Bras Pneumol. 2017;43(5):472-486.

38 Nota técnica sobre as mudanças no tratamento da tuberculose no Brasil para adultos e adolescentes. Ministério da Saúde. Brasília, 2009.

\section{Table 1}

Table 1 Source of data and independent variables under study 


\begin{tabular}{|c|c|c|}
\hline \multirow{11}{*}{$\begin{array}{l}\text { ndividual and social } \\
\text { laracteristics }\end{array}$} & Independent Variables & Classes \\
\hline & Date of Death & Date \\
\hline & \multirow[t]{2}{*}{ Gender } & Female \\
\hline & & Male \\
\hline & Age & Continuous \\
\hline & \multirow[t]{2}{*}{ Ethnicity } & White / Oriental \\
\hline & & Afrodescendant \\
\hline & \multirow[t]{2}{*}{ Educational Level } & 8 years of schooling or more \\
\hline & & 7 years of schooling or less \\
\hline & \multirow[t]{2}{*}{ Marital Status } & Married / Common-Law Marriage \\
\hline & & $\begin{array}{l}\text { Single / Widowed / Separated or } \\
\text { Divorced }\end{array}$ \\
\hline \multirow{12}{*}{ Comorbidities } & \multirow[t]{2}{*}{ Type of Entry } & New case \\
\hline & & Re-entry or Retreatment \\
\hline & \multirow[t]{2}{*}{ Institutionalised } & No \\
\hline & & Yes \\
\hline & \multirow[t]{2}{*}{ Examination: X-ray } & Normal \\
\hline & & Yes, suspicious results \\
\hline & \multirow[t]{2}{*}{ Clinical category } & Pulmonary \\
\hline & & Extrapulmonary \\
\hline & \multirow[t]{2}{*}{ Aggravation - Use of alcohol } & No \\
\hline & & Yes \\
\hline & \multirow[t]{2}{*}{ Aggravation - Diabetes Mellitus (DM) } & No \\
\hline & & Yes \\
\hline \multirow{18}{*}{$\begin{array}{l}\text { perational: examinations and } \\
\text { eatment** }\end{array}$} & \multirow[t]{2}{*}{ Examination: Bacilloscopy } & Negative \\
\hline & & Positive \\
\hline & \multirow[t]{2}{*}{ Culture } & Negative \\
\hline & & Positive \\
\hline & \multirow[t]{2}{*}{ Medication used: Rifampicin } & Yes \\
\hline & & No \\
\hline & \multirow[t]{2}{*}{ Medication used: Isoniazid } & Yes \\
\hline & & No \\
\hline & \multirow[t]{2}{*}{ Medication used: Pyrazinamide } & Yes \\
\hline & & No \\
\hline & \multirow[t]{2}{*}{ Medication used: Ethambutol } & Yes \\
\hline & & No \\
\hline & \multirow[t]{2}{*}{ Medication used: Streptomycin } & Yes \\
\hline & & No \\
\hline & \multirow{2}{*}{$\begin{array}{l}\text { Medication used: Other drugs (second line } \\
\text { TB drugs) }\end{array}$} & Yes \\
\hline & & No \\
\hline & \multirow[t]{2}{*}{ Supervised treatment -DOTS } & Yes \\
\hline & & No \\
\hline
\end{tabular}

*Source: Mortality Information System -SIM

**Source: Disease Notification Information System -SINAN

Figures 


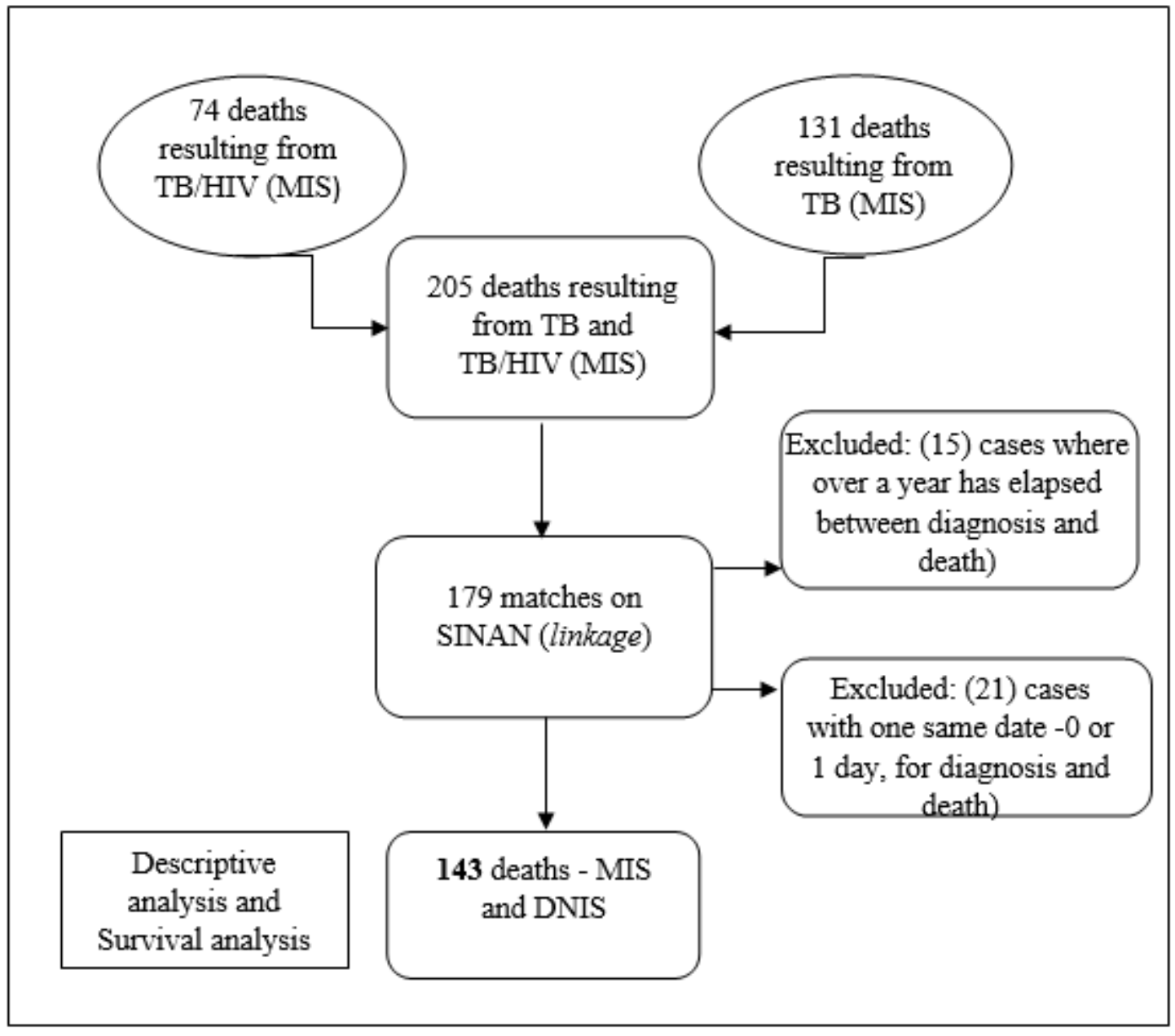

Figure 1

Flow chart of deaths analysed in this study 


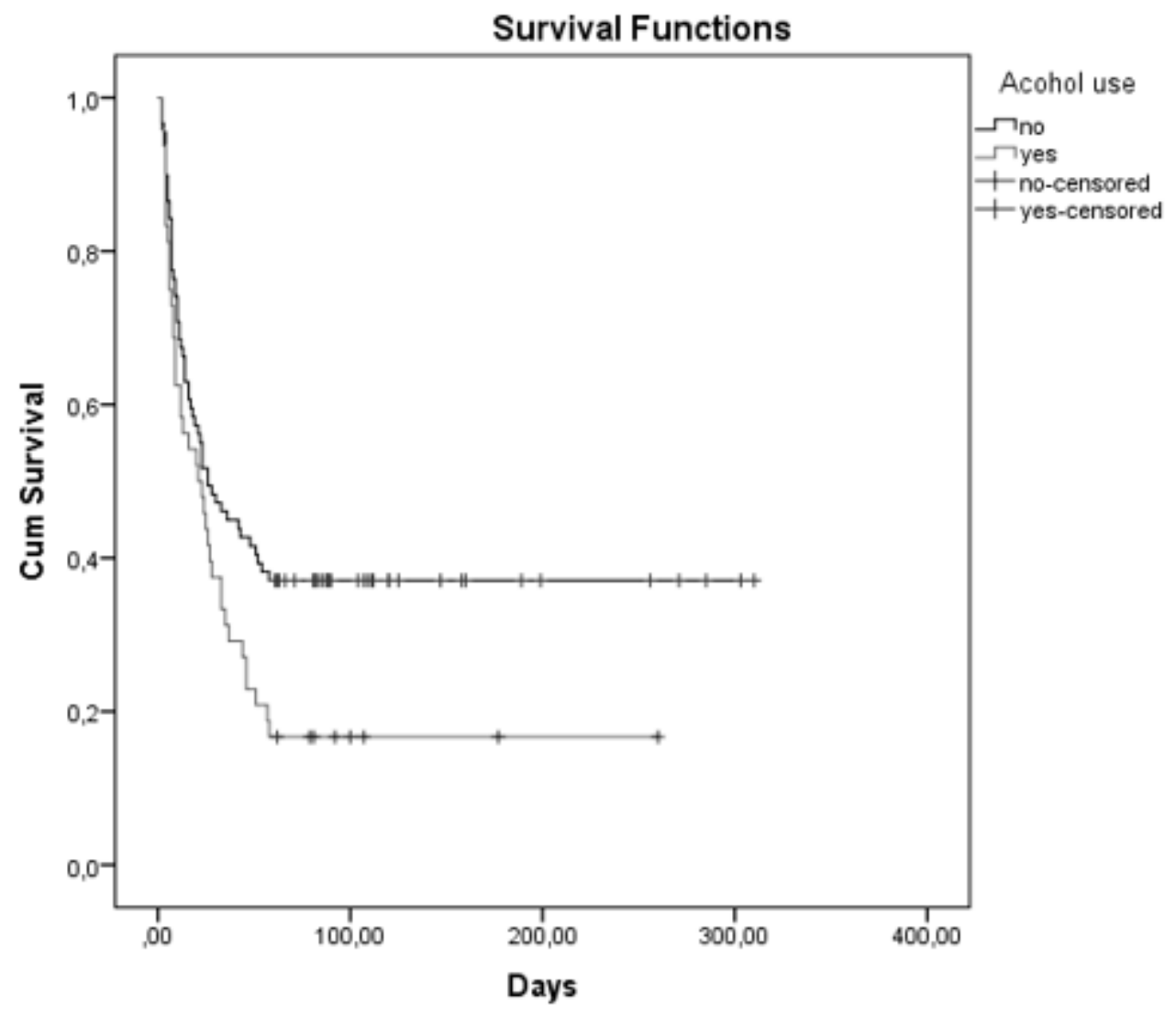

Figure 2

Curves obtained in the Kaplan-Meier survival analysis, with regard to disease aggravation by alcohol consumption in patients who died of TB and TB-HIV. Curitiba (2008-2016). 


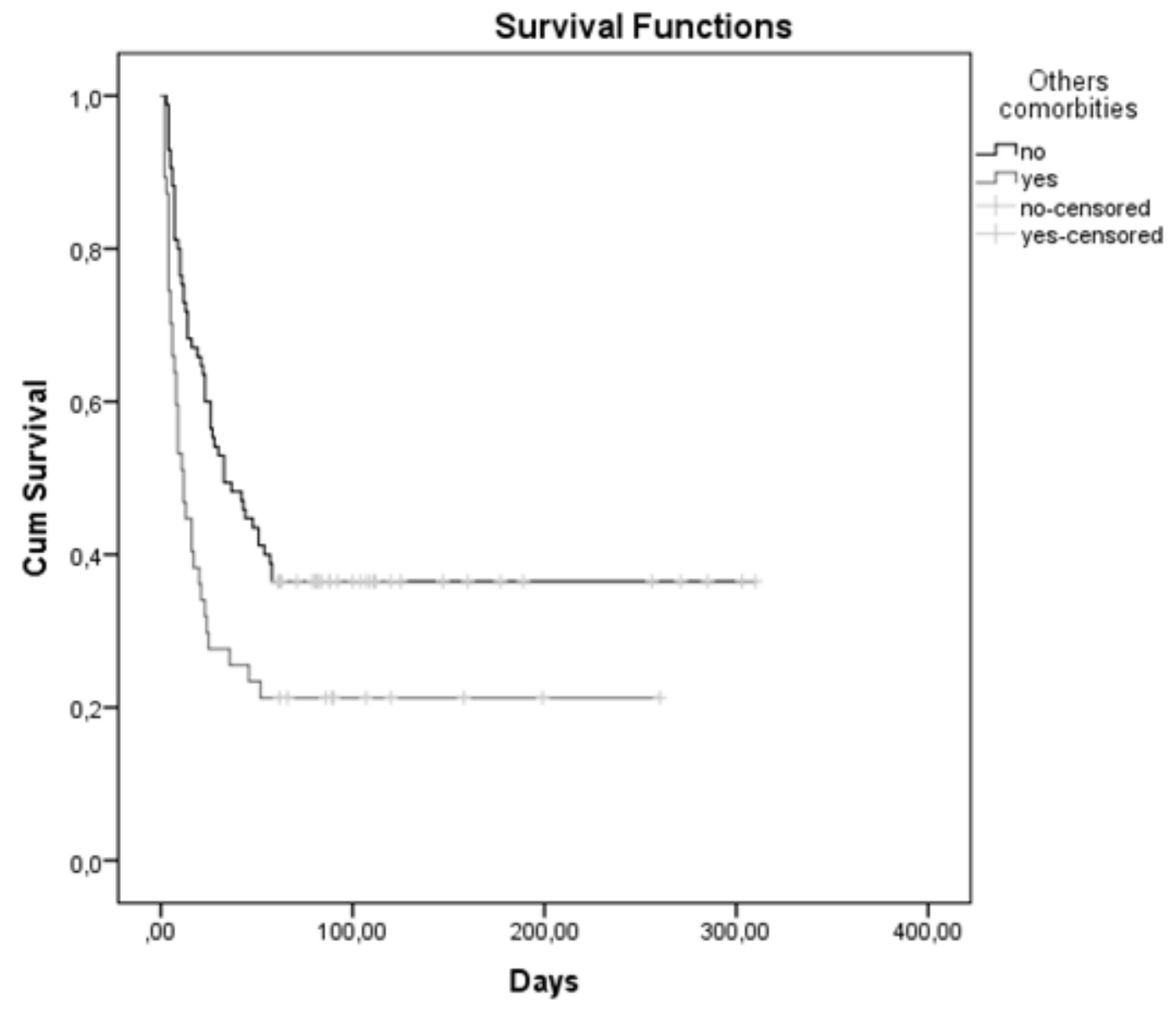

Figure 3

Curves obtained in the Kaplan-Meier survival analysis, with regard to disease aggravation by others comorbidities in patients who died of TB and TB-HIV. Curitiba (2008-2016). 